BEduManageRs Journal

Borneo Educational Management and Research Journal, Vol.2, No.1, 2021

ISSN: 2747-0504

\title{
Manajemen Sumber Daya Manusia Universitas Kutai Kartanegara
}

\author{
M Sjafruddin Achmad ${ }^{1}$, Susilo $^{2}$, Hasbi Sjamsir ${ }^{3}$ \\ Universitas Mulawamran \\ e-mail: doktormp@fkip.unmul.ac.id, sjamsirhasbi@yahoo.com, olisusunmul@ gmail.com
}

\begin{abstract}
Education is a government effort to educate the people of Indonesia, as mandated in the opening of the Constitution 1945, Human resources education is an important factor for the success of an education that must be managed with the most, because with the management of human resources education this educational institution can produce quality graduatesto realize the quality of the college graduates are required a qualified HR lecturer through the management of human resources in the University of Kutai Kartanegara. Human Resource Management (MSDM) is managing recruitment, selection, awarding, efforts to maintain assessment and promotion of personnel to gain the welfare or sanction of the institutions. The research objectives are: (1) to describe the mechanism of HR recruitment. 2 To describe the efforts to increase HR capability. (3) to describe the HR career level. (4) to describe the welfare of human resources. (5) to describe the process of termination or termination of human resources at Kutai Kartanegara University. This method of research uses a case study method with a qualitative approach. Data collection techniques are conducted with; Interviews, observations, photography, and documentation. Data was analyzed by the interactive model Milles Huberman (1994), namely; Data collection, data reduction, display data, and conclusion. Data validity checks are conducted to test credibility, transferability, dependability and confirmability. The results of the study found (1) The recruitment of resources lecturer in education and teaching is determined by the quality of lecturers. (2) Improving the resource capability of lecturers measured through performance. 3 Career Enhancement lecturer conducted with the implementation of college followers (4) Lecturers get guaranteed income, based on the performance report of lecturers (5) dismissal and sanctions system and award based monitoring, performance of lecturers using a written record system.
\end{abstract}

Keywords: Management, Human Resources, Universitas Kutai Kartanegara

\section{PENDAHULUAN}

Pendidikan merupakan suatu upaya pemerintah untuk mencerdaskan rakyat Indonesia, sebagaimana yang diamanatkan dalam Pembukaan Undang-Undang Dasar 1945. Tugas dari amanat dalam undangundang tersebut dalam implementasinya membagi kewenangan pendidikan berada pada pemerintah yaitu Menteri Riset, Teknologi dan Pendidikan Tinggi untuk perguruan tinggi baik negeri maupun swasta, sedangkan pendidikan tingkat Sekolah Dasar dan Sekolah Menengah Pertama di kelola oleh pemerintah Kabupaten/Kota, sedangkan
Sekolah Menengah Atas dikelola oleh Pemerintah Propinsi, dan semua tingkat pendidikan dari Sekolah Dasar, Sekolah Menengah Pertama dan Menengah Atas dikoordinasikan oleh Pemerintah Provinsi.

Pendidikan tinggi yang ada di daerah adalah turut membangun peradaban yang oleh Nata (2012) dengan cara; (1). Menghasilkan para intelektual yang andal dan professional sesuai dengan bidang masingmasing, (2). Menyebarkan gagasan dan pemikiran yang fisik, inovati, (3). Menerapkan konsep pendidikan yang holistic, yakni pendidikan yang tidak hanya menekankan pembinaan fisik, pancaindera, dan intelektual, melainkan juga 
BEduManageRs Journal

Borneo Educational Management and Research Journal, Vol.2, No.1, 2021

ISSN: 2747-0504

mempertakam intuisi, estetika, moral, dan intelektual.

Peningkatan mutu dan kualitas pendidikan merupakan dambaan seluruh penyelenggara pendidikan tidak terkecuali pendidikan tinggi sebab hanya dengan pengelolaan pendidikan yang bermutu, mereka dapat memenangkan persaingan, namun upaya meningkatkan mutu tersebut tidaklah mudah. Upaya peningkatan mutu memerlukan usaha yang serius dan bersungguh-sungguh dengan melibatkan unsur-unsur baik internal maupun eksternal. Berbagai upaya perbaikan mutu pendidikan telah banyak dilakukan, akan tetapi pada kenyataannya kurang atau bahkan tidak berhasil. Setidaknya terdapat beberapa kelemahan umum yang terjadi pada perguruan tinggi (PT) di Indonesia tidak dapat menjadi PT yang berkelas dunia, di antaranya: a) sistem pengelolaan yang buruk, b). sumber daya yang rendah, c). penguasaan bahasa internasional yang rendah, d). pendanaan yang seret, e). peran serta masyarakat yang masih sangat terlalu minim, dan f). pola pikir sebahagian civitas akademika yang masih perlu ditransform dan di asah terus menerus. Secara singkat dapat dikatakan bahwa kompleksitasnya cakupan permasalahan pendidikan seringkali tidak dapat terpikirkan secara utuh dan akurat oleh penyelenggara pendidikan. Perguruan tinggi tidak hanya perlu dilihat sebagai pusat ilmu pengetahuan, pusat penelitian, dan pusat pengabdian kepada masyarakat. Peneliti menetapkan fokus pada kajian Manajemen Sumber Daya Manusia di Universitas Kutai Kartanegara.

\section{KAJIAN TEORI}

Dessler (2014) mendefinisikan MSDM "human resource management is the process of acquiring, training, appraising, and compensating employees, and attending to their labor relations, health and safety, and fairness concerrns."

Donald L.W. (2015) dapat diuraikan bahwa manajemen SDM merupakan perencanaan, pengorganisasian, pengarahan, dan pengawasan atas pengadaan, pengembangan, kompensasi, pengintegrasian, pemeliharaan, dan pemutusan hubungan kerja dengan maksud untuk mencapai tujuan organisasi secara terpadu.

Manajemen SDM yang dikaitkan dengan institusi perguruan tinggi merupakan ilmu dan seni yang mengatur pemanfaatan SDM seperti pimpinan, dosen, karyawan, dan mahasiswa secara efektif dan efisien untuk mencapai visi, misi, dan tujuan lembaga pendidikan tinggi secara maksimal. Manajemen SDM dosen dapat meningkatkan kompetensi dan profesionalisme dosen yang pada akhirnya akan memengaruhi peningkatan mutu perguruan tinggi.

Langkah-langkah pengembangan SDM meliputi : mengidentifikasi kebutuhan, menentukan tujuan program pengembangan, merencanakan dan mengembangkan program pengembangan SDM, mengimplementasi program, mengidentifikasi manfaat, dan mengevaluasi dan monitoring program.

Pengembangan dosen sebagai berikut: sistem perekrutan dosen, membentuk pola perspsi antara kualitas kognitif dosen dengan kemampuan beradaptasi dosen pada kultur dan sistem akademis yang diterapkan di lembaga agar tidak terjadi distorsi komunikasi, mekanisme kontrol yang diterapkan oleh perguruan tinggi terhadap proses belajar-mengajar yang dilaksanakan dosen, penghargaan (reward) yang diberikan oleh perguruan tinggi kepada para dosen yang telah memberikan konstruksi positif bagi eksistensi institusi perguruan tinggi itu sendiri.

\section{METODE PENELITIAN}

\section{Tujuan penelitian adalah :}

1. Mendiskripsikan perekrutan sumber daya manusia dosen di Universitas Kutai Kartanegara.

2. Mendiskripsikan peningkatan kapabilitas sumber daya manusia dosen di Universitas Kutai Kartanegara.

3. Mendiskripsikan jenjang karir yang diberikan kepada dosen di Universitas Kutai Kartanegara.

4. Mendiskripsikan kesejahteraan yang diberikan kepada dosen di Universitas Kutai Kartanegara. 
BEduManageRs Journal

Borneo Educational Management and Research Journal, Vol.2, No.1, 2021

ISSN: 2747-0504

5. Mendiskripsikan pemutusan hubungan kerja dosen di Universitas Kutai Kartanegara.

Metode penelitian ini menggunakan metode studi kasus dengan pendekatan kualitatif. Teknik pengumpulan data dilakukan dengan; wawancara, observasi, photografi, dan dokumentasi. Data dianalisis dengan interactive model Milles Huberman (1994), yaitu; data collection, data reduction, data display, dan conclusion. Pengecekan keabsahan data dilakukan uji kredibilitas, transferabilitas, dependabilitas dan konfirmabilitas.

\section{HASIL DAN PEMBAHASAN}

Rekrutmen dosen menggunakan kualifikasi akademik, kompetensi, dan kebutuhan atau formasi dosen yang tersedia di Universitas Kutai Kartanegara sebagai berikut:

Perekrutan sumber daya dosen di bidang pendidikan dan pengajaran ditentukan oleh mutu dosen.mengikuti aturan Aparat Sipil Negara Pusat. Dosen wajib memiliki kualifikasi akademik dan kompetensi pendidik, sehat jasmani dan rohani, serta mempunyai kemampuan menyelenggarakan pendidikan dan pengajaran.kualifikasi akademik adalah tingkat pendidikan yang paling rendah yang harus dipenuhi seorang dosen yang dibuktikan dengan ijazah.

Peningkatan kapabilitas sumber daya dosen di bidang penelitian ditentukan oleh delapan standar penelitian. Pengelola terutama menyiapkan SDM, dana, dan fasilitas penelitian yang memadai untuk menghasilkan penelitian yang bermutu. Motivasi dosen meningkat menulis hasil penelitiannya di jurnal nasional terakreditasi dan jurnal internasional bereputasi serta memiliki haki jika diberi insentif yang memadai. Beban kerja dosen berdasarkan pada perhitungan akumulasi kegiatan pokok, pelaksanaan tugas tambahan, dan kegiatan penunjang. Kegiatan pokok dosen Universitas Kutai Kartanegara adalah melaksanakan tridharma yang terdiri atas: Perencanaan, pelaksanaan, dan pengendalian proses pembelajaran termasuk pembimbingan. Pelaksanaan evaluasi hasil pembelajaran.
Penelitian. Pengabdian kepada masyarakat termasuk pelatihan. Tugas tambahan berupa jabatan struktural yang diemban oleh seorang dosen, misalnya menjadi Ketua Universitas dan Wakil Ketua Universitas. Dosen tetap Universitas Kutai Kartanegara beban kerja minimal $40 \mathrm{jam} / \mathrm{minggu}$, mengajar minimal 9 sks dan maksimal 16 sks, membimbing tugas akhir/skripsi paling banyak 10 mahasiswa per tahun. Beban kerja mengacu pada rasio dosen dan mahasiswa.

Jenjang karir yang diberikan kepada dosen di bidang pengabdian pada masyarakat ditentukan oleh delapan standar pengabdian pada masyarakat. Pengelola terutama menyiapkan SDM, dana, dan fasilitas pengabdian kepada masyarakat yang memadai untuk menghasilkan penelitian yang bermutu. Pengabdian kepada masyarakat dilaksanakan dengan asas, kelembagaan, ilmu amalian dan amal-ilmiah, kerja sama, kesinambungan, edukatif, dan pengembangan. Dosen mendapat jaminan penghasilan, jaminan sosial, penghargaan sesuai kinerja, pembinaan karir, perlindungan hukum dalam melaksanakan tugas, hak kekayaan intelektual (haki), hak paten, dan kesempatan menggunakan sarana dan prasarana pendidikan.Dosen berhak mendapatkan kesempatan meningkatkan kompetensi, memiliki kebebasan akademik, mimbar akademik, otonomi keilmuan, otonomi memberi nilai, menentukan kelulusan, bebas berserikat dalam organisasi profesi.

Kesejahteraan yang diberikan kepada dosen di bidang tridharma perguruan tinggi: (1) peran pimpinan memberikan arahan dan sekaligus memberikan motivasi dan kekuatan serta menumbuhkan etos kerja dosen, (2) penerapan mutu dosen : motivasi, keahlian pribadi, model, mental, visi bersama, pembelajaran tim dan pemikiran sistem, (3) faktor pimpinan, organisasi, media, dan budaya yang merupakan faktor paling dominan dalam mempengaruhi manajemen mutu dosen, (4) konseptual ini disebut mutu dosen berpijak pada asumsi dan kondisi faktual karena mengandung pemikiran hipotetik dilaksanakan secara profesional, efektif, efisien, dan produktif dengan 
BEduManageRs Journal

Borneo Educational Management and Research Journal, Vol.2, No.1, 2021

ISSN: 2747-0504

sembilan langkah konsep baru manajemen mutu dosen.

Pemberhentian hubungan kerja dosen di Universitas Kutai Kartanegara. Dosen berkewajiban melaksanakan tridharma, menciptakan suasana pendidikan yang kondusif, memiliki komitmen profesionalisme, memberi teladan, meningkatkan kompetensi, bertindak objektif, tidak deskriminatif, taat hukum.

\section{KESIMPULAN}

\section{Simpulan}

Berdasarkan hasil penelitian dan pembahasan temuan penelitian, maka simpulan penelitian adalah sebagai berikut:

1. Mekanisme Perekrutan Sumber Daya Manusia di Universitas Kutai Kartanegara. Perekrutan sumber daya manusia dosen di bidang pendidikan dan pengajaran ditentukan oleh mutu dosen. berdasarkan syarat yang ditentukan oleh aturan perekrutan Aparat Sipil Negara Pusat. meliputi: Dosen wajib memiliki kualifikasi akademik dan kompetensi pendidik, sehat jasmani dan rohani, serta mempunyai kemampuan menyelenggarakan pendidikan dan pengajaran.kualifikasi akademik.

2. paya-upaya Peningkatan Kapabilitas Sumber Daya Manusia di Universitas Kutai Kartanegara.

Peningkatan kapabilitas sumber daya manusia dosen di bidang penelitian ditentukan oleh delapan standar penelitian. Pengelola terutama menyiapkan SDM, dana, dan fasilitas penelitian yang memadai untuk menghasilkan penelitian yang bermutu. Motivasi dosen meningkat menulis hasil penelitiannya di jurnal nasional terakreditasi dan jurnal internasional bereputasi serta memiliki haki jika diberi insentif yang memadai.

3. Jenjang Karir Sumber Daya Manusia di Universitas Kutai Kartanegara.

Beban kerja dosen berdasarkan pada perhitungan akumulasi kegiatan pokok, pelaksanaan tugas tambahan, dan kegiatan penunjang. Kegiatan pokok dosen Universitas Kutai Kartanegara adalah melaksanakan tridharma yang terdiri atas: a) Perencanaan, pelaksanaan, dan pengendalian proses pembelajaran termasuk pembimbingan. b) Pelaksanaan evaluasi hasil pembelajaran. c) Penelitian d) Pengabdian kepada masyarakat termasuk pelatihan. Tugas tambahan berupa jabatan struktural yang diemban oleh seorang dosen, misalnya menjadi Ketua Universitas dan Wakil Ketua Universitas. Dosen tetap Universitas Kutai Kartanegara beban kerja minimal 40 jam/minggu, mengajar minimal 9 sks dan maksimal $16 \mathrm{sks}$, membimbing tugas akhir/skripsi paling banyak 10 mahasiswa per tahun. Beban kerja mengacu pada rasio dosen dan mahasiswa.

4. Kesejahteraan Sumber Daya Manusia di Universitas Kutai Kartanegara.

Dosen mendapat jaminan penghasilan, jaminan sosial, penghargaan sesuai kinerja, pembinaan karir, perlindungan hukum dalam melaksanakan tugas, hak kekayaan intelektual (haki), hak paten, dan kesempatan menggunakan sarana dan prasarana pendidikan. Dosen berhak mendapatkan kesempatan meningkatkan kompetensi, memiliki kebebasan akademik, mimbar akademik, otonomi keilmuan, otonomi memberI nilai, menentukan kelulusan, bebas berserikat dalam organisasi profesi. Kesejahteraan yang diberikan kepada dosen di bidang tridharma perguruan tinggi.

5. Proses Pemberhentian atau Pemutusan Hubungan Kerja Sumber Daya Manusia di Universitas Kutai Kartanegara.

Pemberhentian hubungan kerja dosen di Universitas Kutai Kartanegara Dosen berkewajiban melaksanakan tridharma, menciptakan suasana pendidikan yang kondusif, memiliki komitmen profesionalisme, memberi teladan, meningkatkan kompetensi, bertindak objektif, tidak deskriminatif, taat hukum.

\section{Saran}

Sebagaimana kita ketahui bahwa penelitian tentang manajemen pendidikan 
BEduManageRs Journal

Borneo Educational Management and Research Journal, Vol.2, No.1, 2021

ISSN: 2747-0504

secara umum dan manajemen sumber daya pendidikan masih sangat kurang, maka hasil penelitian ini diharapkan dapat menambah kajian dan studi tentang manajemen tersebut dalam lingkungan perguruan tinggi terutama perguruan tinggi swasta. Selain itu pula hasil penelitian ini secara praktis dapat menambah khasanah penerapan ilmu manajemen khususnya dalam bidang pendidikan.

Bagi Universitas lokal penelitian ini dilakukan, hasil peneitian dapat dijadikan acuan dalam menyelenggarakan proses perkuliahan di Universitas tersebut ataupun Universitas-Universitas lain dapat dijadikan acuan untuk penelitian lebih lanjut lagi agar dapat disempurnakan lagi, disesuaikan dengan waktu dan kondisi yang ada pada saat penelitian.

\section{DAFTAR PUSTAKA}

Becker, B.E., \& Huselid, M.A. (2014). Direct estimates of $S D$ and the Implications for utility analysis. Journal of Applied Psychology, 77 (3), 227-233.

Desseler. (2014). Individual differences in output variability as a function of job complexity. Journal of Applied Psychology, 75, 28-42.

Donal. L. W (2015). The Balanced Scorecard-Measures that drove performance. Harvard Business Review, 70, 64-72.

Lingle, J.H., \& Schicmann, W.A. (2014). From Balanced Scorecard to strategic gauges. Is measurement worth it? Management Review, 83 (5), 56-61.
Miles, B. M., \& Huberman, A. M. (1994). Qualitative data analysis: An expended source book (2nd ed., p. 27). California, USA: Sage Publications.

Muldrow, T., Buckley, T., \& Schay, B. (2017). Greating high performance organizations in the public service. Human Resource Management, 41 (3), 341-354.

O'Leary, B.S., Lindbolm, M.L., Whiteford, R., \& Freeman, S.E. (2017). Selecting the best and brightest Leveraging human capital. Human Resource Management, 41 (3), 325-340.

Ostroff, C., \& Bowen, D.E. (2015). Moving HR to a higher level: HR practices and organizational iffectiveness. In K. Klein \& S.W.J. Kozlowski (Eds.), Multilevel theory research and methods in organizations (pp. 211-266). San Francisco: JosseyBass Inc.

Parasuraman, A., Zaithamal, V., \& Berry L.L. (2016). Refinement and reassessment of the SERVQUAL scale. Journal of Retailing, 67, 420-450.

Ulrich, D. (2018). Organizational capability as a competetive advantage: Human resource professionals as strategic partners. Human Resource Planning, 10, 169-184.

Usala, P.D. (2014). Psychometric analysis of the organizational assessment items: Work unit experiences and organizational scales (PRBC No. 9604). Washington, DC: U.S. Office of Personal

Management. 